\title{
Implant survivorship analysis after minimally invasive sacroiliac joint fusion using the iFuse Implant System ${ }^{\circledR}$
}

This article was published in the following Dove Press journal:

Medical Devices: Evidence and Research

23 November 2015

Number of times this article has been viewed

\author{
Daniel J Cher' \\ W Carlton Reckling ${ }^{2}$ \\ Robyn A Capobianco' \\ 'Department of Clinical Affairs, \\ SI-BONE, Inc., ${ }^{2}$ Department of \\ Medical Affairs, SI-BONE, Inc., \\ San Jose, CA, USA
}

Introduction: Surgical revision rate is a key outcome with all permanent implants. The iFuse Implant System ${ }^{\circledR}$ is a permanent implant used to perform minimally invasive sacroiliac joint fusion. The purpose of this study is to determine the surgical revision rate after sacroiliac joint fusion surgery with this system.

Methods: Using two internal sources of information, revision surgeries were identified and linked to index surgeries. The likelihood of revision surgery was calculated using the KaplanMeier life table approach. Predictors of revision were explored.

Results: Four-year survivorship free from implant revision was $96.46 \%$. Revision rate did not differ by sex and was lower for age $>65$. In all, $24 \%$ of revisions occurred within the first 30 days after surgery; $63.5 \%$ occurred within year 1 . Implant survivorship has improved annually since the device was introduced in 2009.

Conclusion: The survivorship rate with this implant is high and improving; the rate is somewhat higher than total hip replacement but lower than that of lumbar spine procedures.

Keywords: safety, sacroiliac joint fusion, iFuse Implant System, revision

\section{Introduction}

The safety and effectiveness of devices used to treat medical conditions are of key concern to physicians, patients, and payors. Several regulatory pathways are available for the commercialization of medical devices in the US. In some cases, devices may be commercialized without the need for premarket clinical data. Even when premarket clinical data are required, trial sample sizes may be too small to detect rare events. Consequently, the US Food and Drug Administration (FDA) requires postmarket surveillance to maintain a reasonable assurance of safety for all medical devices.

Key components of postmarket surveillance include complaint handling ${ }^{1}$ and reporting of events through the Medical Device Reporting regulation (Code of Federal Regulations, Title 21, Part 803). ${ }^{2}$ The former requires a manufacturer to maintain a record of all complaints of which the manufacturer becomes aware. Complaints are defined broadly as any "communication that alleges deficiencies related to the identity, quality, durability, reliability, safety, effectiveness or performance" of the device. ${ }^{2}$ The latter requires manufacturers, importers, and device user facilities (eg, hospitals, surgical facilities, and other health care sites of service) to report certain device-related adverse events as well as product issues (ie, complaints) to the US FDA.

Postmarket tracking of medical device complaints and adverse events can help to uncover risks not foreseen or not quantifiable in the premarket setting. ${ }^{3}$ Data reported through both of these systems have led to the detection of unanticipated complications
Correspondence: Daniel Cher Department of Clinical Affairs, SI-BONE, 3055 Olin Avenue Suite 2200, San Jose, CA 95128 , USA

Tel +I 6502695763

Email dcher@si-bone.com submit your manuscript $\mid$ www.dovepress.com

Dovepress

http://dx.doi.org// 0.2147/MDER.S94885
Medical Devices: Evidence and Research 2015:8 485-492

(c) (i) (9) 2015 Cher et al. This work is published by Dove Medical Press Limited, and licensed under Creative Commons Attribution - Non Commercial (unported, v3.0) License. The full terms of the License are available at http://creativecommons.org/licenses/by-nc/3.0/. Non-commercial uses of the work are permitted without any further permission from Dove Medical Press Limited, provided the work is properly attributed. Permissions beyond the scope of the License are administered by Dove Medical Press Limited. Information on how to request permission may be found at: http://www.dovepress.com/permissions.php 
associated with total hip arthroplasty, ${ }^{4}$ a pelvic mesh, ${ }^{5,6}$ uterine fibroid tumor ablation procedures, ${ }^{7}$ and mechanical heart valves. ${ }^{8}$

Sacroiliac (SI) joint disorders are a well-known medical condition with both surgical and nonsurgical treatment options. Until recently, surgical options have involved decortication of the SI joint and permanent fixation using screws and plates during an open surgical procedure. ${ }^{9}$ More recently, several devices for minimally invasive SI joint fusion have become commercially available. Most of the published literature reports the use of the iFuse Implant System ${ }^{\circledR}$ (SI-BONE, Inc., San Jose, CA, USA). The iFuse Implant System includes a delivery system to place a series of triangular titanium implants coated with a porous titanium plasma spray across the SI joint using a lateral, transarticular approach under fluoroscopic guidance. ${ }^{10}$ In the US, iFuse Implant System is intended for sacroiliac fusion for conditions including sacroiliac joint dysfunction that is a direct result of sacroiliac joint disruption and degenerative sacroiliitis. This includes conditions in which symptoms began during pregnancy or in the peripartum period and have persisted postpartum for more than 6 months. In other geographies, iFuse Implant System is indicated for sacroiliac joint fusion. Placement of the implants does not require full decortication of the joint, as is done in other joint fusion procedures. The implant's shape allows for immediate stabilization of the joint and the titanium plasma spray coating allows for biologic fixation in bone.

As with other permanent implants placed surgically, the rate of surgical revision is a key outcome. Revision surgery in patients who undergo iFuse implant placement can occur early, typically as a result of neural impingement due to malposition, or late due to persistent or recurrent pain. Late pain could be due to implant loosening or failure to achieve bony fusion. Revision surgery can entail implant removal or repositioning, as well as placement of additional implants or other types of interventions.

Revision after minimally invasive SI joint fusion using the iFuse Implant System appears to be uncommon in both mid- and long-term published case series, ${ }^{11-15}$ as well as in two recently completed multi-center prospective trials. ${ }^{16,17}$ An accurate estimate of the revision rate, as well as monitoring any changes in the rate, requires a large number of patients and extended follow-up. In this report, we combine information from company-maintained inventory management and complaints databases to estimate the revision rate after SI joint fusion. We compare the revision rate observed in the commercial setting to those reported in two ongoing prospective clinical trials (INSITE: NCT01681004, and SIFI: NCT01640353), as well as to rates reported with other orthopedic implants.

\section{Methods}

Two databases were used for the current analysis: inventory management and complaints. Since 2009, key data captured for surgeries using the iFuse Implant System have been recorded in an inventory database. These elements include a unique identifier, procedure date, institution, operating surgeon, implant catalog and lot number, and patient sex and age.

In addition, as part of standard postmarket surveillance, the company records and investigates all reported complaints related to the device, regardless of source or mechanism of communication, and stores this information in a database. ${ }^{1}$ Received complaints are individually evaluated for reportability as required by the US FDA's Medical Device Reporting regulation as well as international regulations. ${ }^{2}$ Institutional review board approval was not required for this study as it was based on an analysis of internal company data routinely collected during postmarket surveillance.

Each complaint was manually reviewed and classified according to whether or not it represented a surgical revision. When further information was required, the operating physician was contacted by telephone or email. For the purpose of this study, a revision is defined as the occurrence of an additional surgical procedure on an SI joint treated with the iFuse Implant System for primary SI joint fusion. Index cases that were inconsistent with the device's labeled instructions for use (eg, revision of a failed primary SI joint procedure that used a different implant system) were excluded prior to analysis. Types of revision procedures included: a removal or repositioning of the originally placed implant(s), placement of additional implant(s), the use of non-iFuse implants to provide additional fixation of the originally treated joint, or the surgical debridement and grafting of the SI joint with or without changes to any of the implants. Each revision case in the complaints database was then manually linked to the corresponding index (ie, initial) surgery in the inventorytracking database.

The likelihood of revision after surgery was calculated using the Kaplan-Meier life table approach. Time to revision was calculated as the difference in dates between the index surgery and the first revision surgery. For analysis purposes, inventory data were censored as of July 15, 2014. Follow-up was censored as of July 15, 2015. This ensured that all treated patients had at least 1-year follow-up. Patient vital status information was not available and not collected; therefore, survivorship rates do not account for death due to other causes. Given the relatively young mean age of patients undergoing this procedure (55.8), expected overall survival is high and lack of vital status information is not expected to meaningfully affect calculated rates. Analysis 
was done on a per-side treated basis in order to accurately account for the small number of simultaneous bilateral surgeries. The proportion of simultaneous second sides was low $(432 / 10,956 ; 3.9 \%)$. In five cases, a surgeon who had not performed the initial surgery performed the revision surgery and was unable to provide information on the surgeon who performed the index surgery. These cases were excluded, which results in a slight underestimate of the revision rate (see "Results" section). Revision surgeries were classified by cause: 1) symptomatic malposition (SM), 2) symptom recurrence (SR), with or without implant loosening, 3) persistent pain, 4) infection, 5) fracture, or 6) early revision for asymptomatic implant malposition.

Differences in time to revision were compared using the log-rank statistic. Subgroup analyses were performed: patient age (by decades), sex, unilateral or bilateral surgery, year index surgery was performed, and surgeon. For the purposes of this analysis, bilateral surgery is used to describe fusion of both SI joints in the same surgery and does not include patients who underwent staged bilateral surgery where the two SI joints are fused in separate surgeries. When subgroup information was unavailable, analyses excluded missing values.

Of interest were reasons for changes in revision rates over time. Minimally invasive spinal surgery is known to have a learning curve; perioperative metrics and complications improve with experience. ${ }^{18}$ We examined surgeon learning curve using two methods. First, we ordered surgeon experience by case number (ie, 1st, 2nd, 3rd ... 150th case, etc). Among surgeons who had performed at least 100 cases, we determined whether the likelihood of revision decreased with increased experience (grouping cases by case number: 1-20, 21-50, 51-100, or $>100$ ) with the surgery/device. Second, for surgeons who had performed at least 20 cases, we examined revision rates in the first 20 cases over time categorized according to the year the surgeon's first case was performed. Observed improvement over time in this second analysis could be attributed in part to improved training.

For the per-surgeon analysis, significant differences seen as a result of the log-rank test were investigated further as follows. The ratio of observed cases to expected cases (an output parameter of the log-rank test) was determined. Since random sampling alone can cause an elevated observed/ expected ratio, the lower confidence limit of the ratio was calculated using an exact Poisson method. ${ }^{19}$ Surgeons with observed/expected ratios whose lower confidence limit exceeded 1 were tabulated.

All analyses focused on surgeries and revisions in the US only. Since the number of surgeries performed in 2009 was small, revision rates are not reported beyond 4 years. The revision rate observed in the entire database was compared with revisions occurring during two ongoing prospective clinical trials (Sacroiliac Joint Fusion With iFuse Implant System, SIFI, NCT01640353 and Investigation of Sacroiliac Fusion Treatment, INSITE, NCT01681004) as well as several retrospective studies reported in the literature..$^{11,12,21,22}$

All calculations were performed using $R .^{20}$ Exact Poisson tests were performed using the "exactci" package (version 1.3-1, http://cran.r-project.org/web/packages/exactci/exactci. pdf).

\section{Results}

Between April 2009 and July 15, 2014, 11,416 cases of MIS SI joint fusion with iFuse Implant System took place in the US. Of these, 28 were excluded because their use was inconsistent with the manufacturer's instructions for use. Of the 11,388 remaining, 10,956 (96.2\%) cases were unilateral, 432 (3.8\%) cases were simultaneous bilateral (ie, both sides treated in the same operation), resulting in a total of 11,820 sides treated.

Patients who underwent SI joint fusion using the iFuse implant were predominantly female (58.9\%, Table 1$)$; mean age was 55.8 and $22 \%$ were over the age of 65 . The number of surgeries performed increased per year. In the majority of unilateral cases $(89.6 \%)$, three implants were used. Similarly, six implants (three per side) were used in $87 \%$ of bilateral cases.

During the estimated 336,332 patient-side-months (28,027 patient-side-years) of follow-up, 320 revisions occurred. In five cases, the revision surgery could not be linked to a particular index surgery. Overall, 24\% of revision surgeries occurred in the first month and $63 \%$ occurred within the first 12 months (Table 2).

The 4-year survival rate free from revision surgery was $96.46 \%$ (cumulative revision rate of $3.54 \%$ ). Adjusting for the inability to match five revision cases to index surgeries, the adjusted 4-year survival rate was $96.40 \%$ (adjusted revision rate of $3.60 \%$ ). The revision rate improved substantially over time (log-rank $P<0.0001$, Figure 1), with 1-year revision rates of $9.7 \%, 4.9 \%, 2.0 \%, 1.8 \%, 1.5 \%$, and $1.4 \%$ during 2009, 2010, 2011, 2012, 2013, and 2014, respectively $(P<0001)$. Because revision rates have fallen over time, the observed 4-year revision rate $(3.55 \%)$ probably overestimates the actual current 4-year rate.

The most common reasons for revision surgery were SM (38.4\%) and SR (47.6\%). The majority (86.8\%) of revisions for SM occur within the first 6 months, while most (87.9\%) revisions for SR occur after month 6 . The 4-year probability of revision due to SM was $1.0 \%$; the 4-year probability of revision due to SR was $1.94 \%$. Revision rates for both conditions improved over time $(P<0.0001$ for SM, $P=0.0118$ 
Table I Information from commercial database $(\mathrm{n}=\mid \mathrm{I}, 388)$

\begin{tabular}{|c|c|}
\hline Characteristic & $\mathbf{N}(\%)$ \\
\hline \multicolumn{2}{|l|}{ Sex } \\
\hline Female & 6,709 (58.9) \\
\hline Male & $2,96 \mathrm{I}(26.0)$ \\
\hline Unknown & I,7I8 (I5.I) \\
\hline \multicolumn{2}{|l|}{ Age } \\
\hline$<25$ & $102(0.9)$ \\
\hline $25-35$ & $588(5.2)$ \\
\hline $35-45$ & I,565 (I3.7) \\
\hline $45-55$ & $2,399(21 . I)$ \\
\hline $55-65$ & $2,056(18.1)$ \\
\hline$>65$ & $2,512(22.1)$ \\
\hline Unknown & $2,166(19.0)$ \\
\hline \multicolumn{2}{|l|}{ Year of surgery } \\
\hline 2009 & $31(0.3)$ \\
\hline 2010 & $256(2.2)$ \\
\hline 2011 & $1,254(11.0)$ \\
\hline 2012 & $3,163(27.8)$ \\
\hline 2013 & $4,256(37.4)$ \\
\hline $2014 *$ & $2,428(21.3)$ \\
\hline Unilateral & $10,956(96.2)$ \\
\hline Bilateral & $432(3.8)$ \\
\hline \multicolumn{2}{|c|}{ Number of implants } \\
\hline Unavailable & $313(2.7)$ \\
\hline \multicolumn{2}{|c|}{ Unilateral surgeries } \\
\hline 2 & 701 \\
\hline 3 & 9,545 \\
\hline 4 & 409 \\
\hline 5 & 1 \\
\hline \multicolumn{2}{|c|}{ Bilateral surgeries } \\
\hline 4 & 67 \\
\hline 5 & 15 \\
\hline 6 & 322 \\
\hline 7 & 7 \\
\hline 8 & 8 \\
\hline All & 11,388 \\
\hline
\end{tabular}

Note: *Data cut-off at July 15, 2014.

for SR). In the more recent time period (2012-present, Figure 2), the cumulative 2-year risk of revision was $\sim 2.5 \%$; $0.9 \%$ for SM and $1.07 \%$ for SR.

Kaplan-Meier analysis was used to evaluate other factors potentially predictive of the likelihood of revision. Revision rates were slightly higher with young age $(P=0.024)$ but did not vary by sex $(P=0.193)$. The number of bilateral revision cases $(n=10)$ was too small to determine a meaningful effect. Revision rate varied by index surgeon $(P<0.0001)$. Taking into account the numbers of index surgeries and follow-up time, each surgeon's ratio of observed to expected revisions was calculated, along with confidence intervals and the ratio of observed/expected. In all, 22 surgeons (3.2\% of all surgeons) had observed/expected ratios that were statistically elevated (ie, the lower confidence limit of the exact Poisson confidence interval exceeded 1); 110 revision surgeries were associated with these 22 surgeons, constituting $34.8 \%$ of all
Table 2 Characteristics of revisions ( $n=3 \mid 5)$; cases that could not be linked are excluded

\begin{tabular}{ll}
\hline Characteristic & $\mathbf{N}(\%)$ \\
\hline Sex & \\
Female & $187(59.2)$ \\
Male & $69(21.9)$ \\
Unknown & $59(18.7)$ \\
Age & \\
$<25$ & $5(1.6)$ \\
$25-35$ & $22(7.0)$ \\
$35-45$ & $5 I(16.2)$ \\
$45-55$ & $6 I(19.4)$ \\
$55-65$ & $51(16.2)$ \\
$>65$ & $45(14.3)$ \\
Unknown & $80(25.4)$ \\
Year of index surgery & \\
2009 & $4(1.3)$ \\
2010 & $19(6.0)$ \\
$20 I I$ & $63(20.0)$ \\
2012 & $95(30.2)$ \\
2013 & $95(30.2)$ \\
2014 & $39(12.4)$ \\
Reason for revision & \\
Symptomatic malposition & $121(38.4)$ \\
Recurrence of symptoms & $150(47.6)$ \\
Never improved & $29(9.2)$ \\
Fracture of ilium & $3(1.0)$ \\
Early revision for asymptomatic & $12(3.8)$ \\
implant malposition & \\
Months to revision & \\
Same day & $10(3.2)$ \\
$<I$ & $67(21.3)$ \\
I-3 & $26(8.3)$ \\
$3-6$ & $31(9.8)$ \\
$6-12$ & $66(21.0)$ \\
I2-24 & $82(26.0)$ \\
$24-36$ & $9(2.9)$ \\
$>36$ &
\end{tabular}

Note: *Data cut-off at July 15, 2014.

revisions, yet these surgeons accounted for only $5.4 \%$ of index cases performed.

For the 25 surgeons who had performed more than 100 cases, cases were divided by case number into cases $1-20$, 21-50, 51-100, and $>100$. The 12-month all-cause revision rates progressively decreased $(1.6 \%, 1.1 \%, 0.8 \%$, and $0.74 \%$, respectively, $P=0.0041)$. Of the 138 surgeons who had performed at least 20 cases, the 12-month revision rates during the first 20 cases progressively improved by year the first case was performed $(6.0 \%, 2.5 \%, 1.5 \%, 1.8 \%$, and $0.7 \%$ from 2009 to 2013 , respectively, $P=0.0952$ ). Twelve-month revision rates for cases performed in 2014 could not be calculated, as only a single surgeon had performed 20 cases.

A review of the published literature on the iFuse Implant System showed a revision rate ranging from $0.7 \%$ to $9.1 \%$ over a period of 6 to 40 months. ${ }^{11,12,21,22}$ In an ongoing prospective 


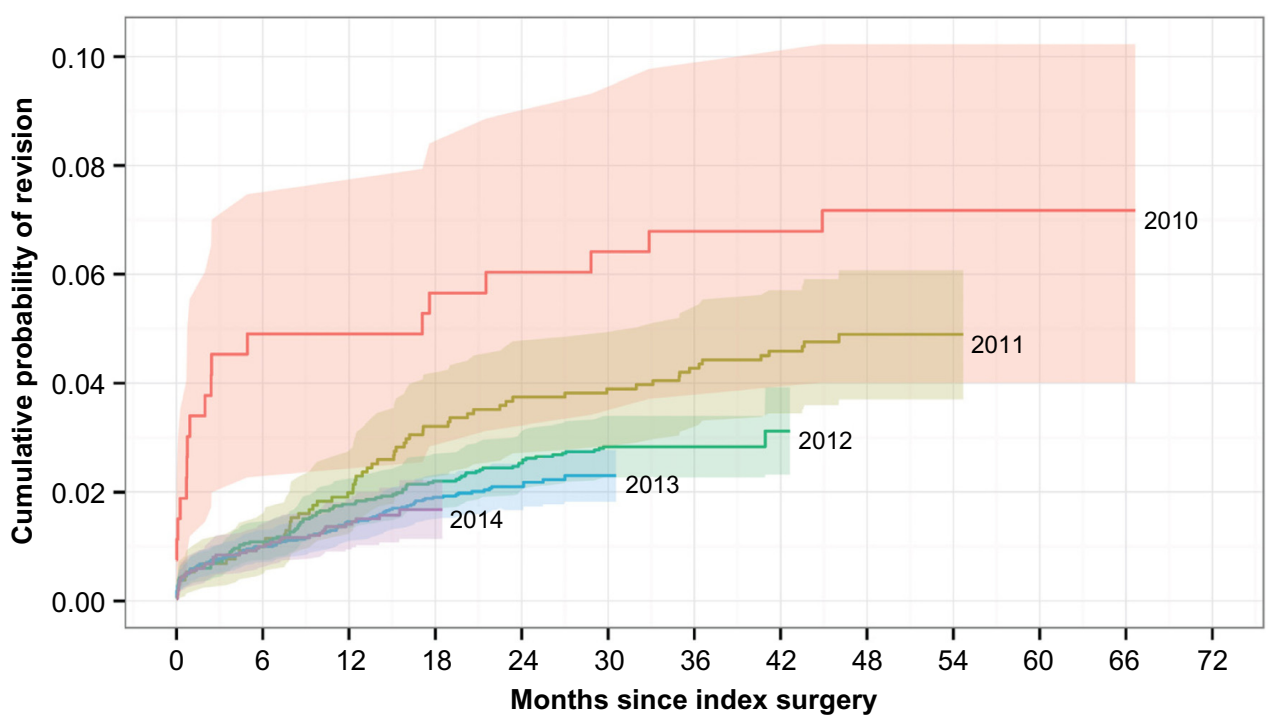

Figure I Cumulative probability of all-cause revision after sacroiliac joint fusion using iFuse Implant System ${ }^{\circledR}$ by year of placement. Note: Shaded regions represent $95 \%$ confidence intervals.

trial of iFuse Implant System (Sacroiliac Joint Fusion With iFuse Implant System, n=172, NCT 01640353), the cumulative 18 -month revision rate was $2.8 \% .{ }^{16}$ In another ongoing prospective randomized controlled trial (Investigation of Sacroiliac Fusion Treatment, n=148, NCT01681004), one of $102(0.98 \%)$ subjects assigned to SI joint fusion using the iFuse implant has undergone revision of the index side. ${ }^{17}$

\section{Discussion}

Three key observations determine the value of surgical procedures with permanent implants: effectiveness (ie, the ability of the procedure/device to improve the target condition), perioperative safety, and long-term safety. A key feature of long-term safety is the need for a revision surgery, an outcome of importance to the patient, surgeon, and payor. Revision rate is a well-accepted endpoint in much of the orthopedic literature.

Our analysis of revision rates associated with the use of iFuse Implant System showed several key findings. First, the revision rate calculated in the nonclinical trial (ie, commercial) setting was similar to that observed in two ongoing prospective trials. The observed rate fell within the values reported in the published literature (which constitutes a subsample of the entire cohort we report herein). ${ }^{11,13-15,21,23}$

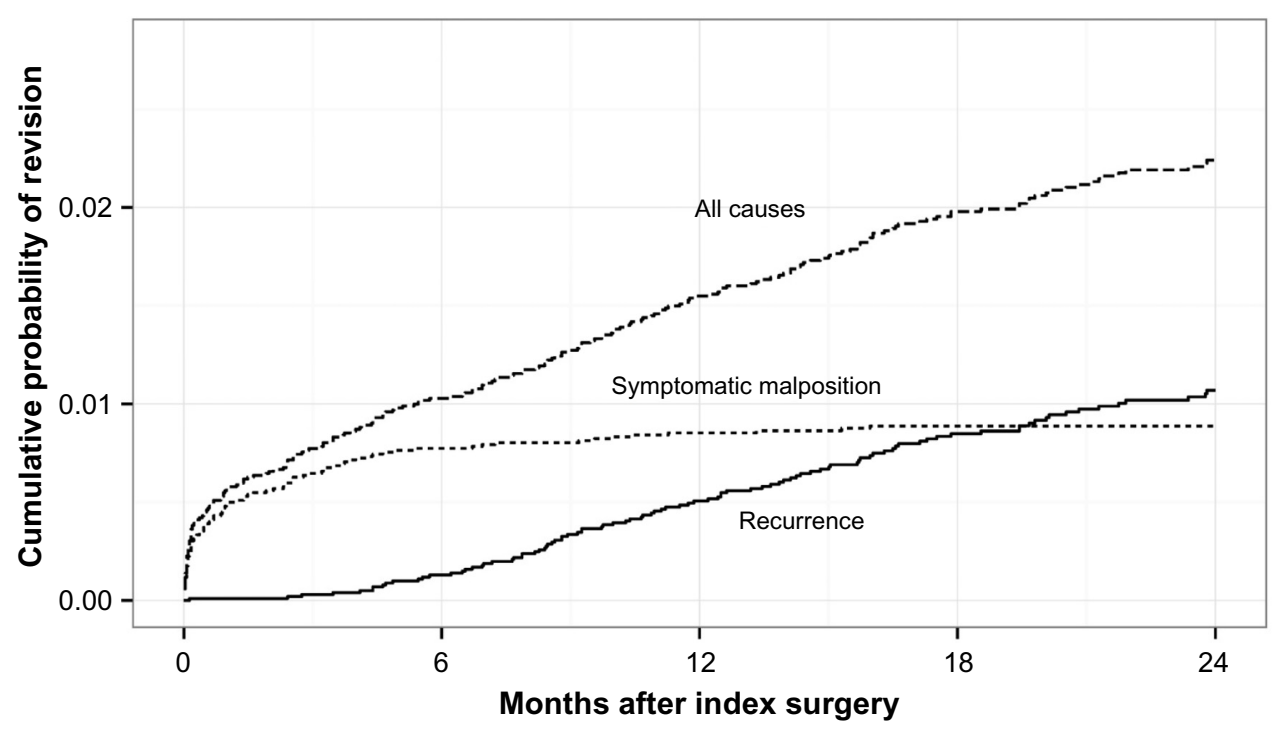

Figure 2 Cumulative probability of revision after sacroiliac joint fusion using iFuse Implant System ${ }^{\circledR}$ for symptomatic malposition, symptomatic recurrence, and all causes for surgeries taking place between 2012 and 2014 . 
Second, the 4-year revision rate of $3.6 \%$ is intermediate when compared with rates reported after other orthopedic procedures. For example, in total hip replacement, a mature technology and surgical procedure, recent figures from Europe indicate 4-year revision rates of $<2 \%,{ }^{24,25}$ in the US, revision rates might be higher ( $4 \%$ at 4 years). ${ }^{26}$ In a retrospective cohort analysis of Medicare claims, 4-year revision rates after lumbar stenosis surgery (decompression or arthrodesis) for lumbar stenosis were $10.6 \%$ and $17.2 \%$ for patients without and with prior surgery, respectively. ${ }^{27}$ The 4 -year revision rate was $10.7 \%$ after simple lumbar arthrodesis and $13.5 \%$ after complex lumbar arthrodesis; device-related complications were reported for $29.2 \%$ of the reoperations. An analysis of discharge registry data from nonfederal acute care hospitals in Washington state revealed 4-year cumulative revision rates of $10 \%-20 \%$ for surgery related to a primary diagnosis of herniated disc, degenerative disc disease, or spondylolisthesis. ${ }^{28}$ The 4-year revision rate for lumbar discectomy, a widely accepted surgical treatment for disc herniation, was $13.8 \%$; this reoperation rate varied by surgeon. ${ }^{29}$ The 5 -year revision rate reported from the CHARITÉ lumbar disc replacement investigational device exemption (IDE) trial was 7.7\%. ${ }^{30}$ Using the US Nationwide Inpatient Sample, the 2-year revision burden for lumbar disc replacement (ie, the proportion of disc replacement procedures that are revisions) was estimated at $11.2 \% .{ }^{31} \mathrm{~A}$ European study of revisions after lumbar disc replacement noted a $10.5 \%$ revision rate of the target area at a mean of 8 years after initial surgery (not counting surgery for adjacent segment degeneration). ${ }^{32}$ In comparison to other commonly performed spine surgeries, the revision rate of $3.6 \%$ after MIS SI joint fusion using the iFuse Implant System appears relatively low.

Revisions after MIS SI joint fusion fell predominantly into two categories: SM or SR. SM typically manifests as new pain down the ipsilateral leg as a result of impingement of the device on local spinal nerve root(s). Not surprisingly, revisions for SM typically occur within the first 30 days after device placement. In fact, $24 \%$ of all revisions occurred in the first 30 days, primarily due to SM. SR may develop when implant placement does not provide sufficient longterm stabilization of the joint. Evaluations of these patients commonly show that one or more of the implants did not adequately cross the joint and engage the sacrum. Thus, revisions for SR generally occur after longer time periods compared to SM. In all, $63 \%$ of all revisions occurred within the first year after implant placement. Overall, however, the implant revision rate was fairly low. Additional potential explanations for late revisions include implant loosening or failure to achieve bony fusion. These details are not routinely collected during standard postmarket surveillance and their occurrence in clinical trials has been uncommon.

Failures of surgical procedures involving implants can fall into three broad categories: surgeon factors, device factors, or patient factors. In our analysis, no revision was attributed to implant failure (ie, breakage). During the time period under study, there were neither major changes to the physical characteristics of the iFuse device nor improvements in the delivery system; thus, these factors are unlikely to contribute to differential risks of implant revision. Our analysis showed that older patients were somewhat less likely to undergo revision, possibly because of increased overall surgical risks in older populations or competing mortality. Revision rate did not vary by sex.

Surgeon experience is often a factor in the risk of adverse events, including revision surgery. ${ }^{33}$ In addition, the learning curve for most minimally invasive spinal procedures has been shown to be relatively long. ${ }^{34-36}$ Our analysis suggests that surgeon experience may play a role with the iFuse implant procedure. Overall, revision rates after MIS SI joint fusion using the iFuse device decreased markedly over time. Revisions for SM, typically resulting from incorrect device placement, also diminished over time. For surgeons who had performed $>100$ cases, 12-month revision rates were lower for the 100 th + case $(0.74 \%)$ versus the first 20 cases (1.6\%). In addition, in all surgeons' first 20 cases, 12-month revision rates progressively decreased over time, with the lowest rates during 2013. These findings suggest improvements in surgeon technique with increased experience and perhaps improved physician training over time. In our analysis, a small number of surgeons (2.6\% of all surgeons) accounted for $34 \%$ of all revisions, suggesting that surgeon proficiency may be a factor in risk of revision. Variation in surgeon expertise may play a role in other procedures. ${ }^{28,33}$

The strengths of this study are three-fold. First, the number of index surgeries performed is captured with high fidelity in our inventory database as both implants and instruments are ordered and purchased directly through the company. Second, a company representative is nearly always in attendance for both index procedures and revisions. Third, although revision is uncommon, because it is an important clinical outcome, and because specialized iFuse instrumentation is typically used during a revision surgery, the occurrence of a revision surgery is likely to be reported to the company with relatively high fidelity.

Our investigation has several limitations. Patient characteristics, other than age and sex, were unavailable, limiting 
our ability to determine whether any other patient factors (eg, body mass index, sacral anatomy, comorbidities) may affect the risk of revision. Although only a small number of known revision surgeries could not be linked to index surgeries, the analysis may not accurately account for all revision surgeries. It is possible that a surgeon not familiar with or trained in the use of the iFuse Implant System performed a revision surgery but failed to report it to the company. It is also possible that revisions took place that involved procedures (eg, bone grafting, placement of alternative devices) that were not reported to or detected by the company; this could result in an underreporting of revision rates. In five cases (1.6\% of all revision cases), we were aware that a revision surgery took place but unable to link the revision to an index surgery; this results in a small underestimation of the cumulative probability of revision. Our analysis is based on data from year 2009 through 2014. In the earlier time period, the number of index surgeries was comparatively small. The 4-year revision rates are therefore based on a follow-up of a relatively small number of patients. However, since revision rates have fallen over time, the reported $3.5 \%$ rate is conservative; the actual current 4-year rate is likely to be lower.

Our analysis does not include death due to other causes, which would result in censoring of observations. Whether such censoring would result in increases or decreases in the calculated revision rate is not known.

Finally, some patients who have inadequate pain relief after SI joint fusion may undergo treatment for another condition. Our analysis does not capture these patients as the procedure provided is not an SI joint revision surgery. Clinical failure rates are best estimated from ongoing prospective studies of SI joint fusion.

Despite these limitations, our investigation demonstrates the value of postmarket surveillance via monitoring manufacturer complaints. Moreover, because index surgeries and revisions are likely captured with high fidelity, we believe our analysis gives a fair representation of revision rates after MIS SI joint fusion using the iFuse Implant System.

\section{Conclusion}

The cumulative rate of revision surgery after SI joint fusion using the iFuse Implant System was $3.6 \%$ at 4 years. This compares favorably with revision rates for other common orthopedic procedures, being somewhat higher than a mature orthopedic technology (total hip replacement) but less than commonly performed lumbar spine surgeries. The revision rate improved annually from 2009, possibly related to a surgeon learning curve or improved training.

\section{Author contributions}

All authors contributed toward data analysis, drafting and revising the paper and agree to be accountable for all aspects of the work.

\section{Disclosure}

All authors are SI-BONE employees. The authors report no other conflicts of interest in this work.

\section{References}

1. Quality System Regulation; Complaint Files. Code of Federal Regulations, Title 21, Part 820. Available from: <http://www.accessdata. fda.gov/scripts/cdrh/cfdocs/cfCFR/CFRSearch.cfm?FR=820.198>. Accessed July 1, 2014.

2. Medical Device Reporting. Code of Federal Regulations, Title 21, Part 803. Available from: <http://www.accessdata.fda.gov/scripts/ $\mathrm{cdrh} / \mathrm{cfdocs} / \mathrm{cfCFR} /$ CFRSearch.cfm?CFRPart=803>. Accessed July 1 , 2014.

3. Leopold SS. Editorial: when 'safe and effective' becomes dangerous. Clin Orthop. 2014;472:1999-2001.

4. Urban RM, Jacobs JJ, Tomlinson MJ, Gavrilovic J, Black J, Peoc'h M. Dissemination of wear particles to the liver, spleen, and abdominal lymph nodes of patients with hip or knee replacement. $J$ Bone Joint Surg Am. 2000;82:457-476.

5. Rice NT, Hu Y, Slaughter JC, Ward RM. Pelvic mesh complications in women before and after the 2011 FDA public health notification. Female Pelvic Med Reconstr Surg. 2013;19:333-338.

6. Koski ME, Rovner ES. Implications of the FDA statement on transvaginal placement of mesh: the aftermath. Curr Urol Rep. 2014;15:380.

7. Stephenson J. FDA warns against procedure used in removing fibroids. JAMA. 2014;311:1956.

8. Brown SL, Bright RA, Tavris DR. Medical Device Epidemiology and Surveillance. Chichester: John Wiley \& Sons; 2007.

9. Buchowski JM, Kebaish KM, Sinkov V, Cohen DB, Sieber AN, Kostuik JP. Functional and radiographic outcome of sacroiliac arthrodesis for the disorders of the sacroiliac joint. Spine J. 2005;5:520-528.

10. Heiney J, Capobianco R, Cher D. Systematic review of minimally invasive sacroiliac joint fusion using a lateral transarticular approach. Int J Spine Surg. 2015;9:40.

11. Sachs D, Capobianco R, Cher D, et al. One-year outcomes after minimally invasive sacroiliac joint fusion with a series of triangular implants: a multicenter, patient-level analysis. Med Devices Evid Res. 2014;7: 299-304.

12. Rudolf L. Sacroiliac Joint Arthrodesis-MIS technique with titanium implants: report of the first 50 patients and outcomes. Open Orthop J. 2012;6:495-502.

13. Vanaclocha V, Verdu-Lopez F, Sanchez-Pardo M, et al. Minimally invasive sacroiliac joint arthrodesis: experience in a prospective series with 24 patients. J Spine. 2014;3:7.

14. Rudolf L, Capobianco R. Five-year clinical and radiographic outcomes after minimally invasive sacroiliac joint fusion using triangular implants. Open Orthop J. 2014;8:375-383.

15. Gaetani P, Miotti D, Risso A. Percutaneous arthrodesis of sacro-iliac joint: a pilot study. J Neurosurg Sci. 2013;57:297-301.

16. Duhon BS, Cher DJ, Wine K, Kovalsky D, Lockstadt H. Triangular titanium implants for minimally invasive sacroiliac joint fusion: a prospective study. Glob Spine J. Epub 2015 Aug 11.

17. Polly DW, Cher DJ, Wine KD, et al. Randomized controlled trial of minimally invasive sacroiliac joint fusion using triangular titanium implants vs nonsurgical management for sacroiliac joint dysfunction: 12-month outcomes. Neurosurgery. 2015;77:674-691.

18. Ahn J, Iqbal A, Manning BT, et al. Minimally invasive lumbar decompression - the surgical learning curve. Spine J. Epub 2015 Aug 11 . 
19. Garwood F. (i) Fiducial limits for the Poisson distribution. Biometrika. 1936;28:437-442.

20. R Core Team (2013). R: A Language and Environment for Statistical Computing. Available from: <http://www.R-project.org/>. Accessed September 1, 2014.

21. Smith AG, Capobianco R, Cher D, et al. Open versus minimally invasive sacroiliac joint fusion: a multi-center comparison of perioperative measures and clinical outcomes. Ann Surg Innov Res. 2013;7:14.

22. Ledonio CG, Polly DW, Swiontkowski MF. Minimally invasive versus open sacroiliac joint fusion: are they similarly safe and effective? Clin Orthop Relat Res. 2014;472:1831-1838.

23. Duhon B, Cher DJ, Wine KD, Lockstadt H, Kovalsky D, Soo CL. Safety and 6-month effectiveness of minimally invasive sacroiliac joint fusion: a prospective study. Med Devices Evid Res. 2013;6:219-229.

24. Garellick G, Kärrholm J, Rogmark C, Herberts P. Swedish hip arthroplasty register. Annual Report; 2010. Available from: $<$ http://linkmedi cal.ru/data/AnnualReport-2010-eng.pdf > . Accesssed July 5, 2015.

25. Clarke A, Pulikottil-Jacob R, Grove A, et al. Total hip replacement and surface replacement for the treatment of pain and disability resulting from end-stage arthritis of the hip (review of technology appraisal guidance 2 and 44): systematic review and economic evaluation. Health Technol Assess. 2015;19:1-668.

26. Kurtz SM, Ong KL, Schmier J, et al. Future clinical and economic impact of revision total hip and knee arthroplasty. J Bone Joint Surg Am. 2007;89 Suppl 3:144-151.

27. Deyo RA, Martin BI, Kreuter W, Jarvik JG, Angier H, Mirza SK. Revision surgery following operations for lumbar stenosis. J Bone Joint Surg Am. 2011;93:1979-1986.
28. Martin BI, Mirza SK, Comstock BA, Gray DT, Kreuter W, Deyo RA. Reoperation rates following lumbar spine surgery and the influence of spinal fusion procedures. Spine. 2007;32:382-387.

29. Martin BI, Mirza SK, Flum DR, et al. Repeat surgery after lumbar decompression for herniated disc: the quality implications of hospital and surgeon variation. Spine J. 2012;12:89-97.

30. Guyer RD, McAfee PC, Banco RJ, et al. Prospective, randomized, multicenter Food and Drug Administration investigational device exemption study of lumbar total disc replacement with the CHARITE artificial disc versus lumbar fusion: five-year follow-up. Spine J. 2009;9:374-386.

31. Kurtz SM, Lau E, Ianuzzi A, et al. National revision burden for lumbar total disc replacement in the United States: epidemiologic and economic perspectives. Spine. 2010;35:690-696.

32. Siepe CJ, Heider F, Wiechert K, Hitzl W, Ishak B, Mayer MH. Midto long-term results of total lumbar disc replacement: a prospective analysis with 5- to 10-year follow-up. Spine J. 2014;14:1417-1431.

33. Labek G, Thaler M, Janda W, Agreiter M, Stöckl B. Revision rates after total joint replacement: cumulative results from worldwide joint register datasets. J Bone Joint Surg Br. 2011;93:293-297.

34. Lee KH, Yeo W, Soeharno H, Yue WM. Learning curve of a complex surgical technique: minimally invasive transforaminal lumbar interbody fusion (MIS TLIF). J Spinal Disord Tech. 2014;27:E234-E240.

35. Jhala A, Mistry M. Endoscopic lumbar discectomy: experience of first 100 cases. Indian J Orthop. 2010;44:184-190.

36. Sclafani JA, Kim CW. Complications associated with the initial learning curve of minimally invasive spine surgery: a systematic review. Clin Orthop. 2014;472:1711-1717.
Medical Devices: Evidence and Research

\section{Publish your work in this journal}

Medical Devices: Evidence and Research is an international, peerreviewed, open access journal that focuses on the evidence, technology, research, and expert opinion supporting the use and application of medical devices in the diagnosis, treatment and management of clinical conditions and physiological processes. The identification of novel

\section{Dovepress}

devices and optimal use of existing devices which will lead to improved clinical outcomes and more effective patient management and safety is a key feature. The manuscript management system is completely online and includes a quick and fair peer-review system. Visit http://www. dovepress.com/testimonials.php to read real quotes from authors. 